\title{
Imaging Techniques for the Assessment of Myocardial Perfusion
}

\author{
Laura Jáni', Lehel Bordi', Mirabela Morariu', Tiberiu Nyulas², István Kovács², Annabell Benedek', \\ Imre Benedek ${ }^{1,2}$
}

${ }^{1}$ Center of Advanced Research in Multimodality Cardiac Imaging, Cardio Med Medical Center, Tîrgu Mureș, Romania

2 University of Medicine and Pharmacy, Tîrgu Mureș, Romania

\section{CORRESPONDENCE}

\begin{abstract}
Lehel Bordi
Str. 22 Decembrie 1989 nr. 76

540124 Tîrgu Mureș, Romania

Tel: +40 265217333

E-mail: bordi_lehel@yahoo.com
\end{abstract}

\section{ARTICLE HISTORY}

Received: 16 October, 2016

Accepted: 22 November, 2016

Laura Jáni • Str. 22 Decembrie 1989 nr. 76, 540124 Tîrgu Mureș, Romania. Tel: +40 265217 333. E-mail: jlaura15@yahoo.com

Mirabela Morariu • Str. 22 Decembrie 1989 nr. 76 540124 Tîrgu Mureș, Romania. Tel: +40 265217333. E-mail: mirabela.morariu@yahoo.com

Tiberiu Nyulas • Str. Gheorghe Marinescu nr. 38 540139 Tîrgu Mures, Romania. Tel: +40 265215551. E-mail: tiberiu.nyulas@gmail.com

István Kovács • Str. Gheorghe Marinescu nr. 38 540139 Tîrgu Mureș, Romania. Tel: +40 265215551. E-mail: kov istvan@yahoo.com

Annabell Benedek - Str. 22 Decembrie 1989 nr. 76, 540124 Tîrgu Mureș, Romania. Tel: +40 265217333. E-mail: annabell.benedek@yahoo.com

Imre Benedek • Str. Gheorghe Marinescu nr. 38 540139 Tîrgu Mures, Romania. Tel: +40 265215551

E-mail: imrebenedek@yahoo.com

\begin{abstract}
One of the most significant causes of heart failure is coronary heart disease and subsequent left ventricular dysfunction. The prognosis and perioperative mortality are influenced by left ventricular function, which is also an important predictor marker following revascularization. The evaluation of myocardial perfusion is of utmost importance in patients who present several symptoms before choosing cardiac catheterization as treatment. The evaluation of myocardial perfusion and myocardial viability leads to superior diagnostic and treatment algorithms, thus resulting in an important improvement in the outcomes of patients with coronary artery disease. Color Doppler myocardial imaging, single-photon emission computed tomography (SPECT), contrast perfusion echocardiography, positron emission computed tomography (PET) and magnetic resonance imaging (MRI) are currently used methods for assessing myocardial perfusion. This review aims to summarize the benefits and disadvantages of each of these techniques.
\end{abstract}

Keywords: myocardial perfusion, viability, stunning, hibernation, revascularization

\section{BACKGROUND}

One of the most significant causes of heart failure is determined by the consequence of coronary heart disease - left ventricular dysfunction. ${ }^{1}$ The prognosis and perioperative mortality of this disease are influenced by left ventricular function, an important indicator for the appropriateness of revascularization therapies.

The relevance of left ventricular function was also analyzed in the CASS registry, which included 20,088 patients with previous coronary bypass graft surgery. Their results showed that the 4-year survival rates were significantly lower for patients with an impaired function of the left ventricle, regardless of the number of vessels affected by coronary atherosclerosis. ${ }^{2}$

Ischemic cardiomyopathy can lead to transient, reversible systolic dysfunction, or in severe cases to irreversible loss of function of the left ventricle. ${ }^{3}$ According to the degree of ischemia, myocardial viability is classified into myocardial necro- 
sis, myocardial stunning and myocardial hibernation. The stunned myocardium can recover within 2 weeks in the absence of ischemia; however, if the ischemic trigger persists, the stunned myocardium becomes hibernating, requiring revascularization for its functional recovery. ${ }^{4}$ It is difficult to differentiate between these stages of ischemia, but in the last 30 years there have been important developments in the imaging methods used for the evaluation of myocardium function, viability and perfusion.

A reduced myocardial perfusion represents a precocious change in the ischemic cascade. ${ }^{5}$ The evaluation of myocardial perfusion is essential in patients who present several ischemic symptoms before choosing cardiac catheterization as a treatment option. The assessment of myocardial perfusion and the evaluation of myocardium viability, with the aim of achieving superior diagnostic and therapeutic algorithms, can lead to important improvements of outcomes. ${ }^{6}$

There are several methods of assessing myocardial viability in clinical practice today. Echocardiography is a noninvasive imaging technique, widely available at a low cost, that can quantify myocardial contractility and assess coronary perfusion in the ischemic territories. With stress echocardiography, we can create a transient condition of reversible myocardial ischemia. Stress can be achieved by physical exercise or medication. ${ }^{7,8}$ Color Doppler myocardial imaging, single-photon emission computed tomography (SPECT), contrast perfusion echocardiography, positron emission computed tomography (PET) and magnetic resonance imaging (MRI) are various methods of assessing myocardial perfusion. ${ }^{9}$ Each of these techniques has its benefits and disadvantages, which are summarized in this manuscript.

\section{FUNCTIONAL STATUS OF THE MYOCARDIUM IN CORONARY HEART DISEASE (CHD)}

The term "viable myocardium" describes a dysfunctional myocardium that is able to retrieve its normal function. ${ }^{10}$ Retrospective studies have described the importance of viability tests, which are included in the process of noninvasive examinations in symptomatic patients, and which have significantly improved in-hospital and 1-year outcomes. ${ }^{11}$ The more viable myocardium is present, the better the regain of left ventricular function after revascularization. ${ }^{12}$

The term "hibernating myocardium" suggests a transient condition of the viable myocardium, a contractile dysfunction that disappears after revascularization. ${ }^{10}$ The hibernating myocardium should be differentiated from the stunned myocardium and from transient left ventricular (LV) dysfunction occurring due to stress-induced isch- emia. Although stunned myocardium can recover its function spontaneously, in the case of hibernating myocardium this is only possible after revascularization. ${ }^{13}$

"Stunned myocardium" refers to a short-term condition demonstrated in the laboratory, when the total occlusion of a coronary artery that lasts 5 to 15 minutes (a time that is not associated with cell death) causes a fault in the regional kinetics of the $\mathrm{LV}$ that persists for hours or days after reperfusion. ${ }^{14}$ In patients with CAD, repeated episodes of transient ischemia may lead to cumulative stunning, which could be the cause of chronic post-ischemic LV dysfunction. Chronic left ventricular dysfunction is one of the consequences of multiple transient ischemic episodes. ${ }^{15}$

\section{ECHOCARDIOGRAPHY FOR THE ASSESSMENT OF MYOCARDIAL PERFUSION}

\section{Stress echocardiography}

Dobutamine stress echocardiography (DSE) is usually performed to assess the contractility of the myocardium. Myocardial infarction, particularly transmural infarction induces regional wall akinesia. If the infarction is recent, and there still is viable myocardium, stress echocardiography can identify if the loss of contractility in different myocardium segments is reversible. Small doses of dobutamine $(5 \mu \mathrm{g} / \mathrm{kg} / \mathrm{min})$ usually lead to temporary regain of contractility; however, dobutamine can also trigger a deterioration of myocardial function if higher doses are administered. This so-called "biphasic response" is a significant predictor for regaining myocardial cell functionality after coronary revascularization. ${ }^{16,17}$ Stress echocardiography is a widely-used method with a high sensitivity and specificity. ${ }^{18}$

\section{Myocardial contrast echocardiography}

The gas-filled microbubbles used in this imaging technique as contrast agents are smaller than red blood cells $(<7 \mu \mathrm{m})$, and they remain blocked in the intravascular space. ${ }^{19}$ The newest method for the assessment of perfusion is using ultrasound energy that destroys the microbubbles, after achieving a steady-state concentration of the contrast agent in the bloodstream. ${ }^{20,21}$ The lack of contrast enhancement suggests the absence of viable myocardium, the presence of myocardial cell necrosis and an impaired microcirculation. ${ }^{22}$

This technique has been used to reveal the segment of myocardium function during coronary artery occlusion and to evaluate tissue reperfusion after revascularization. 
Speckle tracking with adenosine is another method of evaluating myocardial perfusion. When a coronary stress is present, the viable myocardium segments increase the speed of longitudinal contractions, but the non-viable segments remain unchanged. Ran et al. showed in a study that adenosine stress test has a sensitivity of $83.9 \%$ and a specificity of $81.4 \%$ for identifying viable myocardium. ${ }^{23}$

Color Doppler myocardial imaging is a new technique, which is used to assess myocardial wall motion. This new imaging modality may improve the ultrasound evaluation of myocardial ischaemia. ${ }^{24}$

The benefits of imaging techniques based on echocardiography are represented by their low cost, wide availability of equipment and the avoidance of ionizing radiation.

\section{PET AND SPECT - GOLD STANDARD METHODS FOR THE EVALUATION OF MYOCARDIAL PERFUSION}

\section{PET}

Positron emission tomography (PET) has been considered the gold standard of myocardial perfusion imaging. Its strength was established by the incorporation of radionuclides into biochemical molecules, and as a quantitative method, it is used to evaluate myocardial perfusion, contractile function, glucose uptake etc. ${ }^{25}$ Various studies have described the high specificity and sensibility of this method in the diagnosis of cardiovascular disease.

There are several tracers used for myocardial perfusion, such as ammonia, rubidium (Rb-82), or fluorodeoxyglucose (FDG). The insulin resistance of some patients with heart failure may lead to errors in myocardial glucose uptake. ${ }^{26}$ Segments with irreversible ischemia are represented by regions with low FDG uptake and reduced myocardial blood flow. Viable myocardium cells present an increased glucose uptake. ${ }^{27}$ The myocardial uptake of ammonia also illustrates myocardial viability and perfusion. ${ }^{28}$

The stunned region of the myocardium normally uptakes both FDG and ammonia, the hibernating myocardium has a decreased uptake of ammonia but normal or amplified uptake of FDG, and the infarcted area has decreased uptake capacity for both tracers. ${ }^{29}$

The main benefits of PET over SPECT are improved spatial resolution, attenuation correction as an inherent component of the technology, and the tracers used in PET for absolute quantification of perfusion are more easily applied in dynamic scanning. PET is a method with high diagnostic accuracy and specificity for detecting an- giographically significant coronary artery stenoses..$^{30}$ The most important limitation of PET is the high cost.

\section{PET-CT}

This new hybrid imaging method has been developed to simultaneously assess significant myocardium changes caused by ischemia, as well as the coronary anatomy. This may significantly improve the diagnosis and management algorithms of subjects with CAD, first of all by saving time. This imaging technique does not have clarified limitations yet. 31

\section{SPECT}

Single-photon emission computed tomography (SPECT) uses gamma rays, and it evaluates myocardial perfusion and viability, being widely available. It can be applied both at rest and during stress conditions induced by exercises or pharmacologic agents, for the assessment of inducible ischemia due to coronary stenosis. SPECT images show the uptake and distribution of the tracer in the functional myocardial tissue, and also the relative blood flow to several segments of the myocardium. ${ }^{32}$ The potassium analog thallium-201 (Tl-201) was the first tracer used to identify myocardial viability, and myocardial uptake depends of the regional flow. ${ }^{33}$ SPECT has multiple disadvantages, including poor spatial resolution, limited detection of subendocardial perfusion defects and limited detection of significant left main stenosis or multi-vessel disease. ${ }^{34}$ Technetium-99m labeled tracers have more advantages, such as fast elimination from the organism or low radiation exposure to the patient. ${ }^{35}$

\section{MRI DETERMINATION OF MYOCARDIAL VIABILITY}

Cardiac MRI (CMR) is a noninvasive technique, considered the new gold standard imaging procedure for the analysis of myocardial perfusion. CMR can evaluate myocardial perfusion at rest and in stress conditions, and it has a high sensitivity in diagnosing myocardial ischemia caused by acute coronary disease. Recent studies show the ability of CMR to detect microvascular obstruction, which apparently leads to significant cardiovascular complications if the interventional treatment is not timely performed. ${ }^{36}$ The technique is performed using chelated-gadolinium contrast, and it is able to provide information about myocardial perfusion, left ventricular ejection fraction, wall kinetics, and the extent of fibrosis. ${ }^{37}$ 
A meta-analysis by Nandalur et al. showed that CMR holds a high sensitivity and specificity in diagnosing atherosclerotic coronary artery disorders. ${ }^{38}$

Different studies have proved the importance of detecting microvascular obstruction with this noninvasive imaging method; therefore, the assessment of myocardial perfusion in resting conditions has an increased prognostic value in the period following an acute myocardial infarction. Significant improvements of technological innovation in CMR may occur in the future. ${ }^{39}$

\section{CONCLUSIONS}

The assessment of myocardial perfusion for establishing a diagnosis of myocardial ischemia is a significant step in the management of symptomatic patients with coronary artery disease before revascularization therapies. Echocardiographic modalities, nuclear medicine imaging techniques and cardiovascular magnetic resonance are methods that can evaluate myocardial perfusion. All these methods hold several advantages and disadvantages, but are widely used to improve the management and outcomes of patients following myocardial revascularization therapies. Further developments are required to improve the diagnostic and prognostic utility of imaging evaluation of myocardial perfusion, in order to achieve a targeted personalized therapy in patients with a high cardiovascular risk.

\section{CONFLICT OF INTEREST}

Nothing to declare.

\section{ACKNOWLEDGEMENT}

This research was supported via the research grant no. 103545/2016, contract number 43/05.09.2016, entitled "High performance multimodal MRI/CT imaging platform, for applications in computational medicine, nanoparticles and hybrid imaging for the research of atherothrombotic disorders - CARDIO IMAGE" financed by the Romanian Ministry of European Funds, the Romanian Government and the European Union.

\section{REFERENCES}

1. Remme WJ, Swedberg K, Task force for the diagnosis and treatment of chronic heart failure, European Society of Cardiology. Guidelines for the diagnosis and treatment of chronic heart failure. Eur Heart J. 2001;22:15271560 .

2. Mock MB, Ringqvist I, Fisher LD, et al. Survival of medically treated patients in the Coronary Artery Surgery Study (CASS). Circulation. 1982;66:562568.
3. Opie LH. The ever expanding spectrum of ischemic left ventricular dysfunction. Cardiovasc Drugs Ther. 1994;8(Suppl2):297-304.

4. Brauwald E, Kloner RA. The stunned myocardium: prolonged, postischemic ventricular dysfunction. Circulation. 1982;66:1146-1149.

5. Nesto RW, Kowalchuk GJ. The ischemic cascade: temporal sequence of hemodynamic, electrocardiographic and symptomatic expressions of ischemia. Am J Cardiol. 1987;59:23C-30C.

6. Salerno M, Beller GA. Noninvasive Assessment of Myocardial Perfusion Circ Cardiovasc Imaging. 2009;2:412-424.

7. Geleijnse ML, Fioretti PM, Roelandt JR. Methodology, feasibility, safety, and diagnostic accuracy of dobutamine stress echocardiography. J Am Coll Cardiol. 1997;30:595-606.

8. Marwick TH. Current status of stress echocardiography for diagnosis and prognostic assessment of coronary artery disease. Coron Artery Dis. 1998:9:411-426.

9. Schwitter J, Wacker CM, Wilke N, et al. MR-IMPACT II: magnetic resonance imaging for myocardial perfusion assessment in coronary artery disease trial: perfusion-cardiac magnetic resonance vs. single-photon emission computed tomography for the detection of coronary artery disease: a comparativemulticentre, multivendor trial. Eur Heart J. 2013;34:775-781.

10. Camici PG, Prasad SK, Rimoldi OE. Stunning, Hibernation, and Assessment of Myocardial Viability. Circulation. 2008;117:103-114.

11. Haas F, Haehnel CJ, Picker W, et al. Preoperative positron emission tomographic viability assessment and perioperative and postoperative risk in patients with advanced ischemic heart disease. J Am Coll Cardiol. 1997;30:1693-1700.

12. Chatterjee K, Swan HJ, Parmley WW, Sustaita H, Marcus HS, Matloff $J$. Influence of direct myocardial revascularization on left ventricular asynergy and function in patients with coronary heart disease. With and without previous myocardial infarction. Circulation. 1973;47:276-286.

13. Schulz R, Heusch G. Hibernating myocardium. Heart. 2000;84:587-594

14. Bolli R. Myocardial 'stunning' in man. Circulation. 1992;86:1671.

15. Barnes E, Dutka DP, Khan M, Camici PG, Hall RJ. Effect of repeated episodes of reversible myocardial ischemia on myocardial blood flow and function in humans. Am J Physiol Heart Circ Physiol. 2002;282:H1603-H1608.

16. La Canna G, Alfieri O, Giubbini R, Gargano M, Ferrari R, Visioli O. Echocardiography during infusion of dobutamine for identification of reversibly dysfunction in patients with chronic coronary artery disease. $J$ Am Coll Cardiol. 1994;23:617-626.

17. Marwick T, D'Hondt A-M, Baudhuin T, et al. Optimal use of dobutamine stress for the detection and evaluation of coronary artery disease: combination with echocardiography or scintigraphy, or both? J Am Coll Cardiol. 1993;22:159-167.

18. Senior R, Kaul S, Lahiri A. Myocardial viability on echocardiography predicts long-term survival after revascularisation in patients with ischaemic congestive heart failure. J Am Coll Cardiol. 1999;33:1848-1854.

19. Kaul S. Assessment of coronary microcirculation with myocardial contrast echocardiography: current and future clinical applications. $\mathrm{Br}$ Heart J. 1995;74:490-495

20. Wei K, Jayaweera AR, Firoozan S, et al. Ultrasound induced microbubble destruction during venous infusion: a novel method in Imaging techniques for the assessment of myocardial hibernation of myocardial blood flow with echocardiography. Circulation. 1998;97:473-483.

21. Meza MF, Ramee S, Collins $T$, et al. Knowledge of perfusion and contractile reserve improves the predictive value of recovery of regional myocardial function postrevascularization: a study using the combination of myocardial contrast echocardiography and dobutamine echocardiography. Circulation. 1997;96:3459-3465.

22. Ragosta M, Camarano G, Kaul S, Powers ER, Sarembok IJ, Gimple LV Microvascular integrity indicates myocellular viability in patients with recent myocardial infarction: new insights using myocardial contrast echocardiography. Circulation. 1994;89:2562-2569.

23. Picano E, Sicari R, Landi P, et al. Prognostic value of myocardial viability in medically treated patients with global left ventricular dysfunction early after an acute uncomplicated myocardial infarction: a dobutamine stress echocardiographic study. Circulation. 1998;98:1078-1084.

24. Sutherland GR, Stewart MJ, Groundstroem KWE, et al. Color Doppler Myocardial Imaging: A New Technique for the Assessment of Myocardial function. Journal of the American Society of Echocardiography. 1994;29:A1-A28.

25. Di Carli MF, Hachamovitch R. Should PET replace SPECT for evaluating CAD? The end of the beginning. J Nucl Cardiol. 2006;13:2-7.

26. Iozzo P, Chareonthaitawee P, Dutka D, Betteridge DJ, Ferrannini E, Camici PG. Independent association of type 2 diabetes and coronary artery 
disease with myocardial insulin resistance. Diabetes. 2002;51:3020-3024.

27. Auerbach MA, Schoder H, Hoh C, et al. Prevalence of myocardial viability as detected by positron emission tomography in patients with ischemic cardiomyopathy. Circulation. 1999;99:2921-2926.

28. Marshall RC, Tillisch JH, Phelps ME, et al. Identification and differentiation of resting myocardial ischemia and infarction in man with positron computed tomography, 18-F-labeled fluorodeoxyglucose and N-13 ammonia. Circulation. 1983;67:766-788.

29. Tillisch J, Brunken R, Marshall R, et al. Reversibility of cardiac wall-motion abnormalities predicted by positron emission tomography. N Engl J Med. 1986;314:884-888.

30. Bateman TM, Heller GV, McGhie Al, et al. Diagnostic accuracy of rest/ stress ECG-gated Rb-82 myocardial perfusion PET: comparison with ECGgated Tc-99m sestamibi SPECT. J Nucl Cardiol. 2006;13:24-33.

31. Knaapen P, de Haan S, Hoekstra OS, et al. Cardiac PET-CT: advanced hybrid imaging for the detection of coronary artery disease. Netherlands Heart Journal. 2010;18:90-98.

32. Sogbein OO, Pelletier-Galarneau M, Schindler TH, Wei L, Wells RG, Ruddy TD. New SPECT and PET radiopharmaceuticals for imaging cardiovascular disease. Biomed Res Int. 2014; 2014:94296033.
33. Mori T, Minamiji K, Kurogane H, et al. Rest injected thallium-201 imaging for assessing viability of severe asynergic regions. J Nucl Med. 1991;32:17181724.

34. Berman DS, Kang X, Slomka PJ, et al. Underestimation of extent of ischemia by gated SPECT myocardial perfusion imaging in patients with left main coronary artery disease. J Nucl Cardiol. 2007;14:521-528.

35. Stabin MG. Radiopharmaceuticals for nuclear cardiology: radiation dosimetry, uncertainties, and risk. J Nucl Med. 2008;49:1555-1563.

36. Hamirani YS, Kramer CM. Cardiac MRI assessment of myocardial perfusion. Future cardiology. 2014;10:349-358.

37. Gerber BL, Raman SV, Nayak K, et al. Myocardial first-pass perfusion cardiovascular magnetic resonance: history, theory, and current state of the art. Journal of Cardiovascular Magnetic Resonance. 2008;10:18.

38. Nandalur KR, Dwamena BA, Choudri AF, et al. Diagnostic performance of stress cardiac magnetic resonance imaging in the detection of coronary artery disease: a meta-analysis. J Am Coll Cardiol. 2007;50:1343-1353.

39. Morton G, Ishida M, Schuster A, et al. Perfusion cardiovascular magneticresonance: comparison of an advanced, high resolution and a standard sequence. Journal of Cardiovascular Magnetic Resonance. 2012:9:34. 